\title{
The Effects of Natural Resource Degradation on Rural Women's Health: A Sociological
}

\author{
Analysis \\ * Maria Saeed (Corresponding Author) \\ ** Dr. Amber Ferdoos \\ *** Aysha Jawaid
}

\begin{abstract}
Natural resource degradation in developing countries is more likely to generate eventual threats of exhaustion. Major changes in weather patterns, seasonal cycles, and crop failure due to heavy rainfall have affected both men and women in rural areas of Pakistan. However, since women in rural areas of Pakistan are actively engaged in natural resource management, they are more likely to bear the brunt of the burden due to their traditional roles of washing, food preparation, water collection, and family care. Under a qualitative research design, the current research paper has focused specifically on how natural resource degradation affects the health of rural women. The research was conducted using thematic analysis, through an in-depth study of the day-to-day activities of rural women and the pressure experienced by them. To do so, sixteen in-depth interviews were conducted with rural women by using interview and observation protocol. The findings revealed that rural women were dedicated to their work despite natural resource degradation they are bound to their household responsibilities, leading to mental and physical stress, as a result, overburdening and unhealthy lifestyles.
\end{abstract}

Key Words: Natural Resource Degradation, Rural Women, Health Deteriorations.

Introduction

The relationship between women and the environment has become more prominent in recent years. Women have been identified as frequent managers of natural resources, environmental stewards, and decision-makers in domestic consumption and production trends in environmental issues (Nasreen, 2012). Women are collectively responsible for natural resource protection and restoration, so the whole process of environmental destruction must be approached from a gender perspective (Jahan, 2008). In Pakistan, women dedicate a considerable amount of time to protect natural resources to ensure survival (Iftikhar et al, 2007). Women work from dawn to dusk because of their traditional roles, i.e. household management, caregiving, cleaning, preparing food, collecting water and firewood, taking care of the young and sick. As a result, women are massively overburdened, and their health suffers as a result. The current study aims to show how rural women's engagement in natural resource management is causing health inequalities, especially in the context of Pakistan, where rural women interact with nature daily, not only as users or consumers but also as producers and managers of natural resources. Since the well-being of rural women has been a neglected aspect of research. Recognizing rural women's health disparities will help rural health care providers, policymakers, and women themselves create and maintain healthy rural lives.

Islam (1993) argued that women particularly vulnerable to environmental degradation should be acknowledged. Sustainable growth, according to Jahan (2008), would be elusive unless women's contributions to environmental management are acknowledged and funded. To find a solution to the problem of natural resource depletion and its impact on rural women's health, it is necessary to explore the subject through an Ecofeminist lens introduced by Aggarwal (1992) in the Indian context, which describes women's environmental concerns in relation to current gender labor division. I believe that by doing so, using qualitative research methodology, a case study approach as a research

* Department of Sociology, International Is lamic University Is lamabad, Pakistan Email: maria.phdsoc44@iiu.edu.pk

** Department of Sociology, International Islamic University Islamabad, Pakistan Email: amber.ferdoos @iiu.edu.pk

*** Department of Sociology, International Is lamic University Islamabad, Pakistan Email: aysha.phdsoc42@iiu.edu.pk 
tool, and in-depth interviews with rural women I will be able to inspire the practical value of Ecofeminism in the context of Pakistan.

\section{Research Question:}

The research question explored in this study is:

How does the degradation of natural resources affect women's health in rural areas of Pakistan?

\section{Lite rature review:}

All over the developing world, women play an important role in environmental management as farmers, stockbreeders, and suppliers of fuel and water (UNEP \& TERI, 1999). Approximately 43\% of rural women work in agriculture or related fields, they are reliant on the environment (Nasrin, 2012). Due to deforestation, global warming, flood, droughts, water shortage, and population growth natural resources are depleting (Abramovitz et al., 2001) which has a negative impact on third-world countries (Jahan, 2008) especially, rural livelihoods (Upaadhyay, 2005) where, women have been disproportionately affected by natural resource degradation as a victim of poverty (Swarn, Samra \& Mittal, 1998) women are responsible for the well-being of their families and rural household management, controlling the ir families' wellness and lifestyles (Khan, 1995; Peluso, 1991; Rached, Rathgeber, \& Brooks, 1996).

Water is a basic necessity for human life and in rural livelihoods, necessary for cooking and other household tasks (Postel, 2003). Women are the primary food sources in the home, as well as the ones who gather firewood and fetch water for cooking, drinking, and washing (Haider, 1995). According to Rao (1991) \& Sutton (2008), the depletion of natural resources has made these activities much more difficult for domestic and non-domestic purposes, and the poor quality water endangers women's health.

In rural areas, women are the primary caregivers for children, the elderly, and the sick, and they are the ones who suffer the most in times of drought, erratic rainfall, or severe storms as their access to natural resources deteriorates (Aragon, Victoria, Miller, Programs, \& State, 2012). Shamim (1995) went on to say that during natural disasters, women's traditional task of meeting the immediate survival needs of their households becomes more difficult. Rural women put in significantly more time and effort to meet regular household needs to keep the home fires burning. Women are more vulnerable to environmental hazards and they have higher rates of chronic disease and life-threatening medical conditions (Nagbrahmam \& Sambrani, 1983; Thorndyke, 2005). Additionally, Environmental disruption, according to Jahan (2008), has detrimental effects on the health, live lihood, and well-being of the general population in both urban and rural areas, especially the most marginalized ones i.e. the women.

Considering the Ecofeminist debate Agarwal (1992) the relationship between rural women and natural resources is largely regarded as ideological, based on a set of values and beliefs that places women in a hierarchical position below men. The concept of Ecofeminism (movements and philosophies that connect feminism and the environment) is believed to have been coined in 1974 by French writer Françoise d'Eaubonne in her book Le Féminisme ou la. Agarwal's most significant research work (1992) referred to Ecofeminism as a body of thinking that has emerged and is still evolving, but that varies with increasing encouragement. Current research work has been inspired by Agarwal (1992) Ecofeminism philosophy, assuming that it can be a useful lens for examining the loss of natural resources and its effect on rural women's health,

\section{Methodology:}

To address the goal of the current study I had developed a qualitative research methodology using an exploratory research strategy. The study employed social constructivism stance to acknowledge rural women's lives by encouraging women to tell their own stories, while interpretivist epistemological approach has been used through interviews and observations as a naturalistic approach of data collection, whereas the case study method as a Strategies of inquiry (Cresswell, 2014) to provide a thorough understanding of the relationship between rural women's health and natural resource degradation.

Rural women were asked to share their experiences with household management and how it relates to natural resource depletion. The current research was carried out in the Punjabi village of "Bhoon" in the Pothwar district. This locale was selected because I belong to the pothwar region, and my family and villagers were extremely helpful in providing me with information about the area where natural resources were degrading, and so it was more convenient and easier for me to choose 
this specific locale. The target population was 250 , comprised up entirely of rural women who worked in the fields and relied on natural resources to survive.

\begin{tabular}{|c|c|c|}
\hline Variables & Frequency & Percentage (\%) \\
\hline \multicolumn{3}{|l|}{ Education level } \\
\hline No formal school & 8 & 50 \\
\hline Primary School & 5 & 31.25 \\
\hline Secondary School & 2 & 12.5 \\
\hline Others & 1 & 6.25 \\
\hline \multicolumn{3}{|l|}{ Husband's occupation } \\
\hline Employed in city & 6 & 37.5 \\
\hline Private business & 3 & 18.75 \\
\hline $\mathrm{Ill} / \mathrm{dis}$ abled & 3 & 18.75 \\
\hline Unemployed & 4 & 25 \\
\hline \multicolumn{3}{|l|}{ Household Income } \\
\hline Under 10,000 & 11 & 68.75 \\
\hline $10,000-25,000$ & 5 & 31.25 \\
\hline
\end{tabular}

Purposive and snowball sampling technique was employed in the selection of sample size. The interviewing guide was first pretested on five respondents, and some gaps were discovered, so I made substantial adjustments to improve the efficiency of the guide.

This study has followed 16 in-depth interviews with rural women about the ir day-to-day activities, the burden they experienced as well as the problems they face. Thus, interviews, observations, and field notes were analyzed for each in-depth interview. Two protocols suggested by Creswell (2014), i.e. interview protocol and observational protocol were used. The Interview protocol is a form used by a qualitative researcher for recording and writing down information obtained during an interview. While, the observational protocol is a form used by a qualitative researcher for recording and writing down information while observing (Creswell, 2014). During the interviews, I stayed with the interview questions and within the stated time limit. I have listened carefully and used a conversational tone of voice and also used observational protocol to take notes. The observational protocol was divided into two columns of descriptive notes and reflective notes (Cresswell, 2014). The descriptive notes included the date and time along with the settings, actions, behaviors, and conversations that the researcher will observe. While reflexive notes included noting my thoughts, ideas, questions, and concerns during the observation.

The data were analyzed using thematic analysis techniques using steps guided by Creswell (2009) by the organization, reading, coding, themes and the description, and interpretation of themes. After conducting in-depth interviews with respondents, the interview and observation procedures were followed, and field notes were read, allowing all descriptive and reflective notes to be organized. Afterward, the data were coded to make the results more understandable, and different codes were combined to create themes, which were then thoroughly clarified and interpreted.

When dealing with the data collected from respondents, ethical concerns were held in mind. The interviews were taped with their permission. Respondents' anonymity was preserved by expressing their answers without disclosing their identities.

\section{Data Analysis:}

This part will provide a very comprehensive thematic analysis of the data about the overall effect of natural resource degradation on the lives of rural women by highlighting the burden they face and how their health deteriorates due to that burden. The research was divided into different themes to provide a more detailed overview, and each theme was analyzed using data provided by rural women.

Daily routine:

Rural women had a full schedule of household chores and they worked for their families from dawn to dusk. They spent almost the whole day working to save their families lives. They have grown accustomed to working hard. The daily activities of women in the village varied depending on the size and structure of their families, except for fetching water, firewood, and taking animals to the jungle for grazing, which was all the same because natural resources in the region affect all rural women equally.

Women work tirelessly at all hours of the day and night. They look after their duties both inside and outside the house. Data from the majority of women stated that women woke up earlier than the rest of the family because they have to prepare breakfast, get dressed, and get their children 
ready for school, and get their husband ready for work as well. They were responsible for building household security, and the selection of necessities throughout the day (i.e. water, firewood, and animal fodder). For all of this, they were preparing food for the rest of the day, waiting for the family to arrive so they can feed them, washing the ir clothes, and cleaning the whole house. Families rely solely on women to survive, so due to strong traditional ties and roles, women were more concerned about their families than about themselves. Despite such a hectic routine; they had not lost faith, and they were committed to the ir jobs and families. But, in my opinion, they were working extremely hard, and their workload was growing as they grow older and their family's needs were increasing as well. Finally, it comes down to the decline in women's health.

\section{Water and fire wood collection:}

Water intake and fuel combustion are essential aspects of everyday rural household needs. In current research work, rural women used to fetch water from a well situated at a distance of $1 / 2 \mathrm{KM}$ from the village, while the jungle from which firewood was collected was $1 \mathrm{KM}$ away from the village. Rural women assisted one another since it was considered their duty. As a result, rural women traveled $1 / 2$ KM to get water from a well for drinking purposes. The number of rounds for fetching water depends on the size and structure of the family.

For the collection of firewood, some women received assistance from male family members, such as sons or husbands. Women who don't have male family members or whose male family members refused to assist them in collecting firewood, collect it on the ir own. Many who do not have a male family member employ workers once a month but they were privileged enough to afford workers.

"I collect firewood on my land in the jungle, and when I go there, I cut them down and carry them on my shoulders, whether it's summer or winter." (Interview with Ayesha).

Cutting firewood is not an easy job, and carrying a huge amount of firewood on one's shoulders is too difficult for a woman to do. They were, however, deeply committed to their work and carry out their duties with dignity. Since it is unusual for the villagers, none of the women replied that they had ever sent their daughters to the jungle to cut firewood.

\section{Natural resource degradation:}

The level of natural resource depletion has been discovered to be growing over the past 7 years in Village "Bhoon". Each season is more difficult than the previous one, but when it rains, the situation is much better. The majority of women said that there was plenty of water and firewood available in the past but as time is passing, natural resources are depleting.

"There has been a huge drought in the village for the past seven years, and there has been an excessive shortage of firewood nearby, and firewood is still decreasing," as narrated. (Interview with Mariyam).

Women used to graze their livestock in the jungle, which was about 2 kilometers away. A few women stated that the housing society projects nearby have taken their land and bladed it, causing the land to shrink, while others posited that rainfall has decreased and the region lacks adequate water, causing the land to dry up. Women stated that in previous years fodder was readily available near their houses, but due to climatic variations the fodder has vanished, and they must now pass through the forest.

\section{Time and distance traveled for fetching water:}

The amount consumed is equal to the amount of time and distance spent collecting water and firewood. Water and firewood are so important to rural people that their absence is unthinkable. The closest water well was $1 / 2$ kilometers away from the village. Since one round of water is inadequate for regular household water consumption, women made a certain number of rounds each time, depending on the size and structure of their family.

"My family consists of five members, and every morning I make five to six rounds to fetch water, which is extremely difficult. It takes her about 2-3 hours.' (Interview with Zainab).

Now, if feeding a family of five takes 2-3 hours, women with larger families struggle even more. They must complete more rounds, and the time and distance traveled are significantly greater. People have reported that when they arrived at the well, there is already a long line of women waiting to fetch water, and they must wait for their turn. In this way, they are consuming more of their time. It is difficult for women to wait for the ir turn in hot summers because there are sunstroke and warmth everywhere. 


\section{Helping Hands:}

According to rural women's responses, each woman had different assistance from the family. Women with young daughters and daughters-in-law were aided by accompanying them to fetch water and wash clothes. Their husband and son assisted them in gathering firewood from the jungle. While, there are some privileged women in the village whose husbands refused to assist them in collecting firewood or who, in the absence of their husbands, when faced a firewood shortage, hire workers to gather firewood for them from the jungle or use the animal extract as a fuel, and some women who are unable to travel such a long distance hire a van and cut firewood there, load it on the van and return.

Following the gathering of firewood, rural women cut it all into pieces and spread it out on their roofs to dry in the sunlight. The woods are capable to burn until they have dried out. While in winter, wet wood is difficult to burn. Women with no helpers do it on their own, with the occasional assistance of their daughters or other rural women in the neighborhood. When it came to handling livestock, the majority of women said they were assisted by their daughters and husbands, while others said they were the sole animal caretakers. These women, on the other hand, were very brave and hardworking, and they performed these tasks without complaining to the other members of the household.

Some women had husbands who moved to cities in search of jobs. Since their needs will not be met unless they earn money. In the absence of men, women were expected to do double duty without the husband's help, completing both their everyday duties and those delegated to them by their spouse. Even, the women were brave and accepted working in place of their husbands because they believed that if they won't work, their household will perish, and they fought hard for their family's survival.

\section{Natural resource collection and women's health:}

Women were suffering from chronic illnesses. They were tired of handling natural resources for their survival because water usage is much more than collection. Women washed their clothes on the canal located at a faraway distance. Similarly, there were several obstacles in their way to the jungle i.e. unsuitable weather, an unpaved route, and they, too, suffered. The care for the collected firewood and fetched water is a big responsibility, household issues, and so on are examples of these barriers. Resulting in sickness. Whether it's a fever, headache, joint pain, body aches, or fatigue, women are primarily responsible for the care of the family's children and sick members. During their sickness, the majority of women put in the same amount of commitment for their families and continue to work hard to survive.

The well water that rural people drink was contaminated. There had been several cases of dogs dropping into the water. As a result, they inquired about the issue with Islamic Scholars. They instructed them to clean up the water using specific Islamic methods. Although the majority of women believed that well water is safe to drink and is clean enough. People aren't conscious of the laws of cleanliness. Some women had claimed that they believe well water is unhealthy to drink, but they have no other alternative. Other females complained of kidney and stomach issues, but they couldn't say whether or not unclean water was to blame. They were cut by chemically toxic sprays over the fields when planting and harvesting, but they had never gone to the hospital or doctor. Insects and rats had also contaminated the village's well water, which was used for drinking. People continued to believe that drinking well water is safe. Women worked tirelessly for their families, helping them at all hours of the day and night, but they and the ir families are afflicted by several chronic and water-borne illnesses.

Rural women were incredibly hard workers, but when they worked beyond their capabilities, they suffered. According to the current research work majority of women claimed that their daughters were extremely helpful in times of illness. While some men assisted women to some degree. One woman narrated,

"When I'm sick, my husband is supportive in certain cases. Even though we don't split our jobs and I have to finish my work but they look after me." (Interview with Zainab)

Some women had supportive husbands who went out of their way to assist them while they were sick. Those women whose husbands were uncooperative seldom complain to their husbands; instead, they concealed the situation, claiming that the ir husbands have difficult responsibilities in towns, making it difficult for them to assist in household chores. Women claimed that the ir family's 
life has been interrupted by their disease, and they must suffer alongside them; the ir husbands support them in acute situations, but not in chronic illnesses.

\section{Coping strategies:}

For coping up with the water needs some residents of the village have installed underground tanks for storing rainwater while others purchased it from outside sources. Instead of fetching water from the well or going to the canal to wash clothes, they used stored water to meet their needs. While some women were unable to travel such a long distance and were also impoverished, they have hired vans for 200 rupees for the collection of water and firewood.

"Villagers are so friendly and support each other to cope with crises; for example, when there is a water shortage and elderly people are unable to fetch water, their neighbors will give them the water they have stored." (Interview with Mariyam)

Villagers supporting each other in times of need is a positive sign. Although some villagers had no plan for dealing with the crisis, they were simply moving on.

"We bought gas cylinders, but we'll only use them in an emergency because we can't afford to cook with it. We only use it when we have guests or when we don't have any other options." (Interview with Fatima)

People couldn't rely on gas cylinders because the prices were much higher than their salaries, so they must rely on firewood instead. Women reported that they burnt animal extracts as fuel to cook their food. However, the animal extract was only a temporary replacement that can be burned in an emergency; women have claimed firewood as their primary source of cooking fuel. Because the villagers couldn't obtain firewood and no financial means to purchase a gas cylinder, they relied on animal extract as a source of fuel.

\section{Coping aid from government/private organizations:}

The majority of the women stated that the government never inquired about their situation. However, when it comes to election time, upper-level officials visited their village and vow to provide water and Sui gas to help them cope with the degradation of natural resources, but they never follow through. "It's the story of every election." (Interview with Fatima).

Sui gas and water from the water supply had been approved in the area 2-3 times, according to the study, but have yet to be installed. Many social workers came to their area, but due to cultural barriers, they were not allowed to speak out.

"Our men won't let us talk in front of other men about the issues of natural resource depletion in our region and the problems we're having because they feel it's against culture, but is it culturally acceptable, however, that we travel such a long distance and that many men see us, often harassing us??" (Interview with Asma)

\section{Discussion:}

According to the findings of current research, women play a critical role in rural life as the primary provider of daily household needs. They are completely dependent on natural resources. Women were mainly responsible for fetching water for drinking, bathing, cooking, and cleaning. During periods of water scarcity, such as during the dry season or drought, women are forced to walk longer distances, wait longer, and rely on lower-quality water to complete household chores, causing mental and physical stress. Especially women with larger family structures are more likely to encounter health problems than women with smaller families, as the workload increases when the family size is larger. The data revealed that men were not typically expected to assist women in their tasks, women found it difficult to keep up with the workload since they were afflicted with chronic diseases such as fever, headache, joint pain, muscle aches, and fatigue.

According to recent studies, natural resources have been degraded at an alarming pace. The majority of respondents stated that they had encountered a water shortage. Rivers, wells/springs, reservoirs, and irrigation canals are the primary sources of drinking water for the majority of people in developing countries (WHO and UNICEF, 2015). The water reservoirs in the current research locale were situated at longer distances, forcing women to travel long distances to gather firewood and fetch water.

Women are the most persecuted group in rural areas, according to the discussion above, and they suffer far more from resource depletion. Since they work hard to ensure the survival of their families and fight the crisis on their behalf, there is a need to pay special attention to the ir health issues to maintain a better rural livelihood. 


\section{Conclusion:}

In Pakistan's rural areas, women play a critical role in natural resource management. My research clearly shows that the survival of rural women in Bhoon village is dependent on natural resources. Over time, the area's natural resource depletion is increasingly growing. However, women are coping by overworking and living, resulting in overburdening and unhealthy lifestyles. By the use of qualitative research methodology, a large amount of data has been gathered. In-depth interviews showed that the amount of time spent handling natural resources is increasing, and that, in addition to time, they are using their double energy to deal with the situation as the cultural barriers play a significant role in the ir marginalization. There have been no federal interventions on this serious issue, and no such initiatives have been initiated, and even if they are, there are cultural obstacles to women's participation. As a result, there is an urgent need to identify the current problem and formulate strategies that take into account the health experiences of rural women to ensure their safety and well-being.

\section{Recommendations:}

In the light of the findings from the research, I am recommending certain measures:

1. To relieve the regular workload of rural women caused by natural resource degradation, the government must provide Sui gas and water supply connections to the village.

2. The government should raise awareness about health care by establishing various healthcare educational programs, primarily aimed at rural women to maintain healthier lifestyles.

3. The village requires a hospital well equipped and with well-trained personnel with laboratories and a pharmacy so that people suffering from water-borne diseases, malaria,

\section{References:} typhoid, and other illness can be treated effectively.

Abramovitz, J., Banuri, T., Girot, P.O., Orlando, B., Schne ider, N., Spanger-Siegfried, E., Switzer, J., \& Hammill, A. (2001). Adapting to climate change: natural resource management and vulnerability reduction, The International Institute for Sustainable Development (IISD).

Agarwal, B. (1992). The Gender and Environment Debate: Lessons from India. Feminist Studies, 18, 119-158. https://doi.org/10.2307/3178217

Aragon, J., Victoria, U., Miller, D., Programs, B., \& State, U. (2012, January 01). Chapter 11: Women and the Environment. Retrieved December 03, 2020, from https://ecampusontario. pressbooks.pub/womenintheworld/chapter/chapter-11-women-and-the-environment/

Creswell, J. W. (2014). Research design qualitative, quantitative, and mixed methods approach. Los Angeles: SAGE Publications.

Haider, R. (1994). Women, Poverty and the Environment. In Rahman, A. Atiq et.al. (eds.), (1994), Environment and Development in Bangladesh. Vol.1, Dhaka: University Press Limited (UPL). Haider, Raana (1995), A Perspective in Development: Gender Focus, Dhaka: UPL

Iftikhar, N., Ali, T., \& Ahmad, M. (2007). Role of rural women in agriculture and their training needs. Journal of Animal and Plant Sciences, 17, 93-95.

Islam, M. (1993). Role of Social Science Research and Activities in Conservation. In "People, Development, and Environment: Complex Interlinkages in Bangladesh". Proceeding of National symposium, held in Dhaka, Bangladesh, 3-4 Nov. 1992, IUCN.

Jahan, M. (2008). The Impact of Environmental Degradation on Women in Bangladesh: An overview. Asian Affairs, 30(2), 5-15.

Khan, S. (1995). The Impact of Environment on Women's Health Status. In Jahan. et.al. (eds.), (1995). Environment and Development: Gender Perspectives, Dhaka: Women for Women.

Nagbrahmam, D., \& Sambrani, S. (1983). Women's Drudgery in Firewood Collection. Economic and Political Weekly, 18(1/2).

Najmun, S. (2008). Ecofeminism: Global and Bangladesh Context. Asian Studies Journal of the Department of Government and Politics, J.U.; 27. Dhaka.

Nasrin, F. (2012). Women, environment and environmental advocacy: challenges for Bangladesh. Asia journal of social sciences and humanities, 1(3), 149-172.

Peluso, N. L. (1991). Women and natural resources in developing countries. Society \& Natural Resources, 4(1), 1-3. doi:10.1080/08941929109380738

Postel, S.L. (2003). Securing water for people, crops, and ecosystems. A new mindset and new priorities. Natural Resources Forum, 27(2): 89-98. 
Rached, E., Rathgeber, E., \& Brooks, D. B. (1996). Water management in Africa and the Middle East challenges and opportunities. Ottawa, Ontario: International Development Research Centre.

Rao, B. (1991). Women and water in rural Maharashtra. Environment and Urbanization, 3(2), 5765. doi:10.1177/095624789100300209

Shamim, I. (1995). Women and Environmental Disaster: Riverine Erosion and Displaced Women as Manager. In Jahan et al. (eds.). Environment and Development: Gender Perspective, Dhaka: Women for Women.

Sutton, S. (2008). The Risk of Technology-Based MDG Indicator for Rural Water Supply.

Swarn Lata Arya, Samra, J. S., \& Mittal, S. P. (1998). Rural Women and Conservation of Natural Resources: Traps and Opportunities. Gender, Technology, and Development, 2(2), 167-185.

UNEP \& TERI (Issue brief). (1999). Annual Evaluation Report

Upadhyay, B. (2005). Women and natural resource management: Illustrations from India and Nepal. Natural Resources Forum, 29(3), 224-232. doi:10.1111/j.1477-8947.2005.00132.x 